\title{
HIP DYSPLASIA IN THE AFRICAN BANTU
}

\author{
A. Roper, Salisbury, Rhodesia \\ From the Department of Surgery, University of Rhodesia, Harari Hospital, Salisbury
}

\begin{abstract}
Dysplasia of the hip is almost unknown in the Bantu peoples of Africa, except in cases of arthrogryposis and in those with partly European ancestry. Evidence is produced to show that the importance of intrinsic genetic factors in hip dysplasia far outweighs that of the extrinsic factors. These are of great importance only if allowed to act on a hip in which genetic factors have already determined dysplasia. Evidence is also produced to contradict the theory that the "piggyback" carrying method used by Bantu mothers is the reason for the immunity from dysplasia of the hip. The absence of "primary" osteoarthritis of the hip is noted, and the range of hip disorders leading to "secondary" osteoarthritis in the adult African is compared with that in the adult European. Three patients are described, one in each of the groups mentioned above, the third having an isolated "typical" congenital dislocation of one hip. The methods of study used were enquiry into obstetric history and into carrying methods, and arthrography to confirm clinical findings. The experience of other surgeons working in Africa is recorded.
\end{abstract}

Salter (1968), in a carefully reasoned article on the aetiology, pathogenesis and possible prevention of congenital dislocation of the hip, separated the condition into "typical" and "atypical teratalogical". The latter includes such conditions as arthrogryposis multiplex congenita, in which hip dysplasia is seen but in which there has been failure of mesodermal development. These patients present many other problems, are "atypical", and are therefore not relevant to any discussion on "typical" hip dysplasia.

Wynne-Davies (1973) stated that hip dysplasia "is almost unknown in the African Bantu". To the author's knowledge, no case of true "typical" congenital dislocation of the hip has been authenticated and documented in an African Bantu baby. Edelstein in South Africa and Huckstep in Uganda (both quoted by Salter 1968) found no evidence of hip instability from the examination of many thousands of newborn pure bred African Bantu babies.

The purpose of this communication is to present three cases of congenital dislocation in African Bantu, to mention the conditions under which hip dysplasia is seen, and to report what the author believes to be the first "typical" congenital dislocation of the hip seen in a pure bred African Bantu neonate.

It is often stated that the reason for the immunity enjoyed by the African Bantu from hip dysplasia is the traditional method used by African mothers of carrying their babies from birth on the back, with the child's hips flexed and abducted. The matter will be discussed later.

Most agree that hip dysplasia has a multifactorial aetiology. The two main factors, in order of importance, are 1) the fundamental genetic factor or factors, and 2) the manifold extrinsic environmental factors acting on the abnormal hip from as early as the fifth or sixth month of pregnancy.

We can only agree with Salter that these factors, acting on the undiagnosed dysplastic hip, are responsible for the increasingly severe pathological changes which occur in all the structures of the hip joint as the child grows older. In short, the environmental factors are powerful, but their effects are secondary to the primary genetic defect.

TABLE I

Detalls of Three Cases of Congenital Dislocation of Hip in Bantu Children

\begin{tabular}{|c|c|c|c|c|c|c|c|}
\hline & $\begin{array}{c}\text { Age } \\
\text { first seen }\end{array}$ & Sex & $\begin{array}{l}\text { Position carried } \\
\text { in neonatal period }\end{array}$ & Right or left & $\begin{array}{c}\text { Other abnormalities } \\
\text { and group }\end{array}$ & Treatment & Result \\
\hline Case 1 (Figs. 1 to 5) & 15 days & Female & Traditional & Right & $\begin{array}{l}\text { Radial club hands. } \\
\text { "Atypical" }\end{array}$ & $\begin{array}{l}\text { Von Rosen splint } \\
\text { for } 5 \text { months }\end{array}$ & Normal hip \\
\hline Case 2 (Fig. 6) & 4 years & Male & Traditional & Right and left & None. "Typical" & No treatment & Unchanged \\
\hline Case 3 (Figs. 7 to 9) & 17 days & Male & Traditional & Right & None. "Typical" & $\begin{array}{l}\text { Von Rosen splint } \\
\text { for } 5 \text { months }\end{array}$ & Normal hip \\
\hline
\end{tabular}

Note: "Typical" and "Atypical" refer to Salter's definition.

A. Roper, F.R.C.S., Senior Lecturer in Orthopaedics, Department of Surgery, Harari Central Hospital, P.O. Box ST 494, Southerton, Salisbury, Rhodesia. 


\section{CASE REPORTS}

The essential facts about the three cases are presented in Table I. The child in Case 1 was of pure Bantu stock. She was born during the summer months, so swaddling with the hips extended could not have been a factor. Follow-up was maintained for four years, and after the splint was discarded the mother was encouraged to maintain the traditional method of carrying (Figs. 1 to 5). so that as in Case 1 swaddling could not be implicated. The duration of follow-up was two and a half years, and the mother was encouraged to use the traditional carrying method after the splint was discarded (Figs. 7 to 9).

\section{DISCUSSION}

The theory that the traditional carrying method used by Bantu mothers is the reason for the virtual immunity

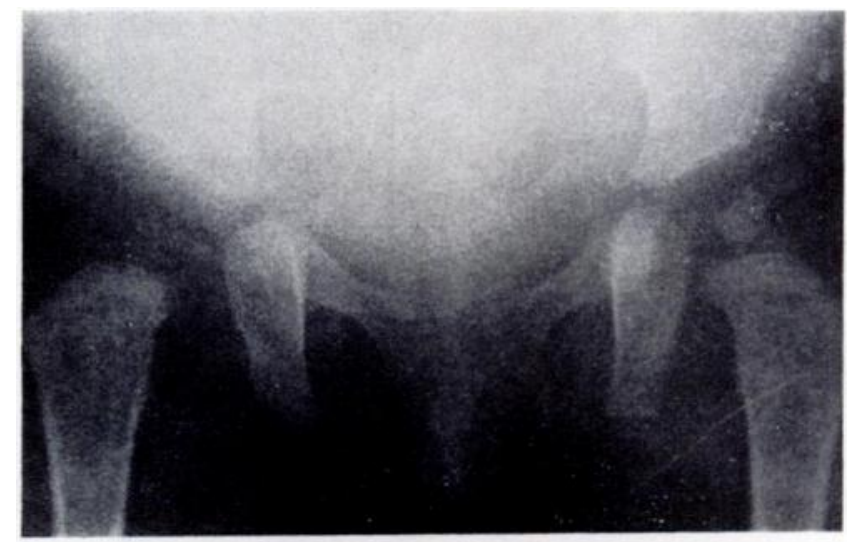

FIG. 1
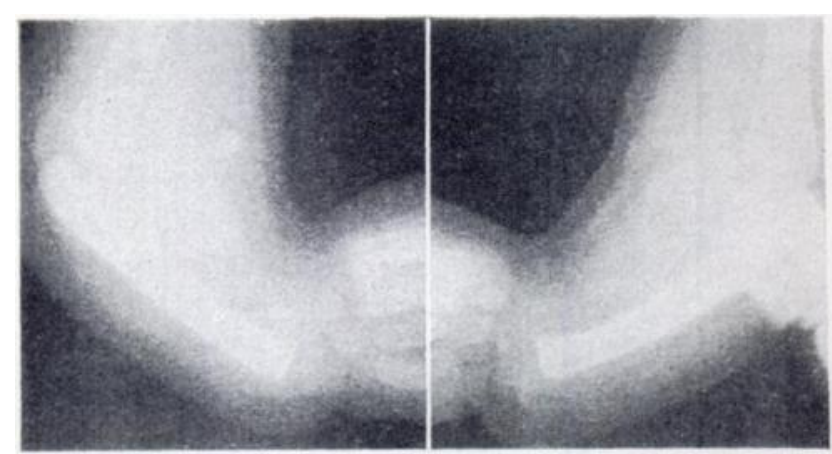

FIG. 2

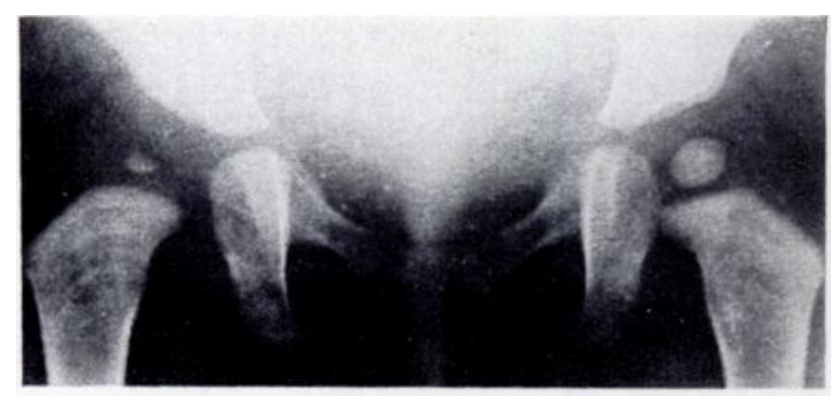

Fig. 4

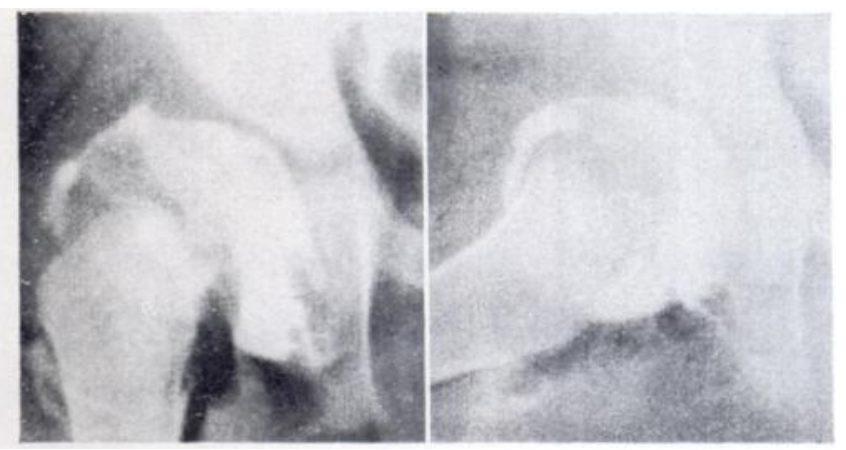

FIi. 3

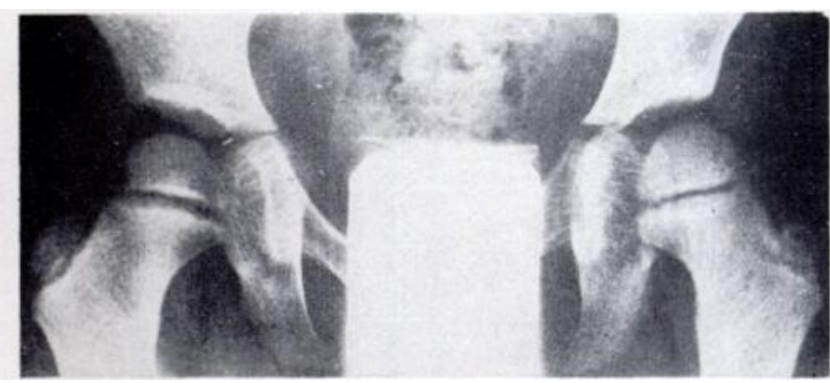

FIG. 5

Case 1. Figure 1-Congenital dislocation of right hip in a girl 15 days old. Figure 2--Associated congenital absence of radii. Figure 3Arthrograph of right hip at 1 month. Figure 4-Right hip at 10 months. Figure 5-Result at the age of 4 years.

The maternal grandmother of the child in Case 2 was Eurafrican. This boy was brought up as an African; the date of his birth was not known, and there was no follow-up (Fig. 6).

In Case 3 the boy was a first-born child, a vertex presentation, and not held up by his legs after birth. He was of pure Bantu stock, born during the summer months, from hip dysplasia enjoyed by the Bantu peoples is convenient, but not satisfactory. Some of the arguments against it may be summarised.

Firstly, hip dysplasia is multifactorial. Extrinsic factors undoubtedly play a large part, but would not do so if the diagnosis was made and effective treatment begun at birth. The genetic factors, or lack of them, 


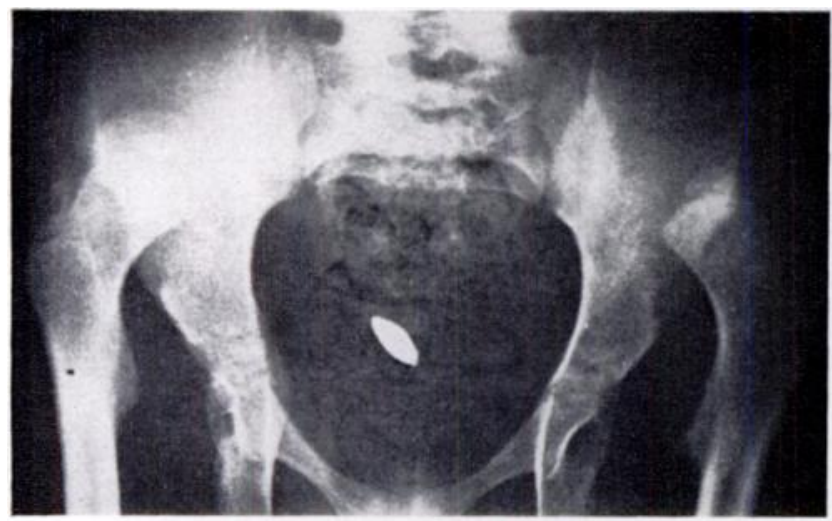

FIG. 6

Case 2-Bilateral untreated congenital dislocation in a boy aged 4 years.

are the root cause; there are known to be "high" incidence communities (Northern Italy) and "low" incidence communities (Hong Kong Chinese). The Bantu must be considered a "very low" incidence community. Even so, for a lifetime among the Bantu people, and those orthopaedic surgeons who have done a great deal of work in African communities, would not see perhaps one baby with hip dysplasia every eighteen months. In short, some cases would "slip through the net" despite the traditional carrying method. The observations of Edelstein and Huckstep carry weight. G. T. du Toit (1974), in a career spanning thirty years of orthopaedic practice among both major races in South Africa, has seen one Bantu patient with "typical" hip dysplasia, a three months' old Zulu girl. The author and a senior colleague who have, between them, seen over 40,000 African out-patients over thirty-five years, have experience of only one "typical" congenital hip dislocation-the patient reported here as Case 3.

Thirdly, Trevor (1967) stated that the incidence ratio in the United States of America between coloured and white is $1: 30$. The former group must be considered therefore a "low" incidence group. Yet in comparison with the African Bantu this incidence is high. The implication is that the powerful influence of European

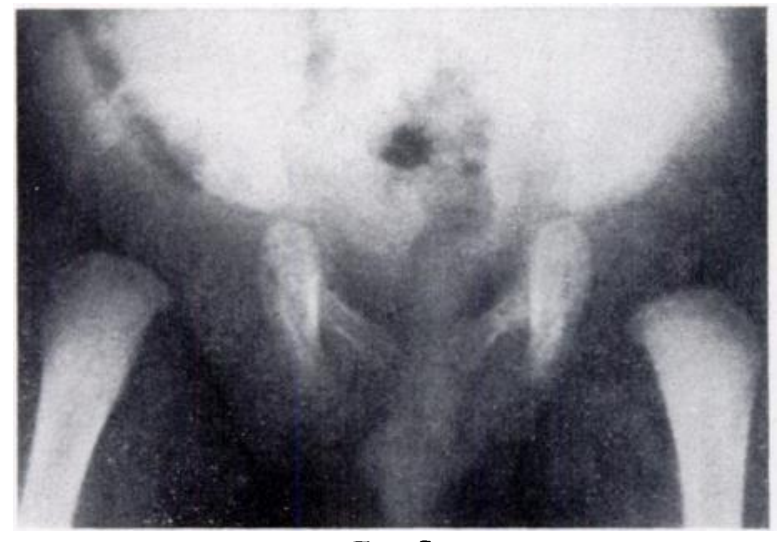

FIG. 7

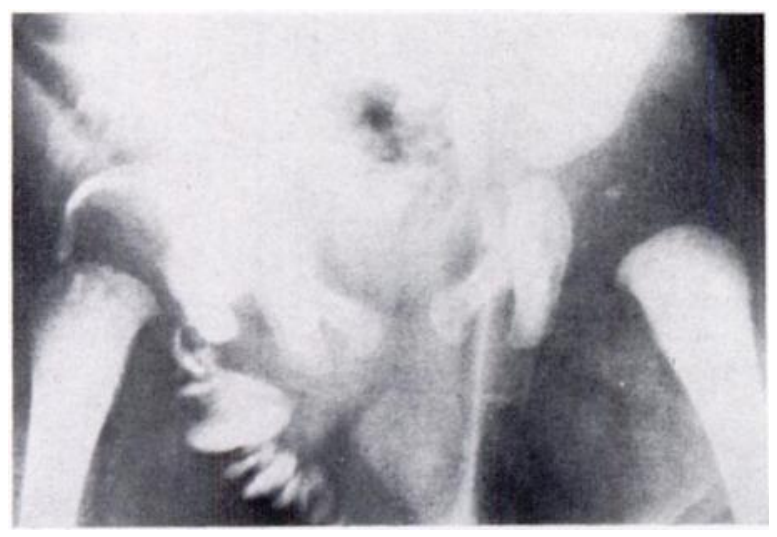

FIG. 8

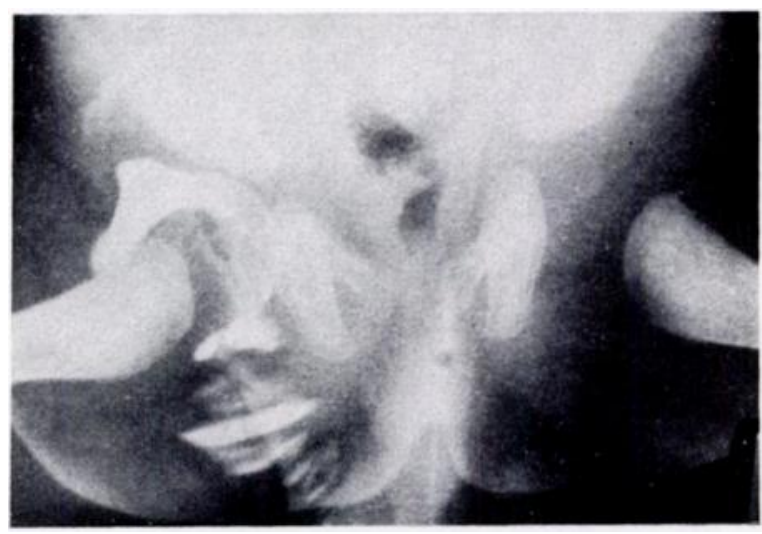

FIG. 9

Case 3. Figure 7-Congenital dislocation of right hip in a boy aged 17 days. Figure 8 -Arthrograph two weeks later, hip dislocation. Figure 9-Arthrograph on the same day, after reduction.

hip dysplasia is seen occasionally in "low" incidence communities who use the traditional Bantu carrying method.

Secondly, even in the "very lowest" incidence groups it is hardly possible that those doctors who have worked genetic factors is responsible, for many American Negroes are not pure-bred Africans. We do not know what percentage of American Negro mothers carry their babies in "traditional" fashion, but suspect it is only a small fraction of the whole. 
Murray (1965) in a review of 200 unselected patients with osteoarthritis of the hip, concluded that 25.5 per cent of the whole had some degree of acetabular dysplasia, and were therefore more correctly designated as having secondary rather than primary osteoarthritis. Furthermore, this group showed a male : female ratio of $1: 4$. This ratio is almost exactly the same as the male: female ratio of congenital dislocation of the hip in "high" incidence communities. Wynne-Davies (1973) considered acetabular dysplasia resulting in a shallow socket to be one of the main aetiological factors in hip dysplasia.
Putti (1933) in Italy, and Gade (1947) in Norway, noted acetabular dysplasia in 40 and 49 per cent respectively in their studies. Both countries are known as "high" incidence areas of congenital dislocation.

Primary osteoarthritis of the hip is almost unknown in the Bantu. Perthes' disease is rare, and epiphysial coxa vara not common. Secondary osteoarthritis in Bantu adults has a different group of primary causes, apart from trauma. Those factors responsible for the primary defects in hip dysplasia are, for practical purposes, absent in the Bantu people.

Addendum-Since this article was submitted for publication a further reference to the occurrence of hip dysplasia in the Bantu has been made by Van Meerdervoort (1974), and furthermore Huckstep (1970) reported twin girls of pure Bantu descent with complete dislocation of both hips and poorly developed acetabula.

Much credit is due to Dr J. Knottenbelt, S.G.M.O. Bindura District Hospital, for making the diagnosis in Case 3. The author also wishes to thank Mr J. H. G. Robertson, Senior Orthopaedic Surgeon, Emeritus, Rhodesian Government, for his help; Professor P. E. S. Palmer, Department of Diagnostic Radiology, University of California, Davis (formerly of Mpilo Central Hospital, Bulawayo) for the films of Case 1; Professor G. T. du Toit of Pretoria University for permission to publish a personal communication; Mr R. Webber, Senior Technician to the Department of Surgery, University of Rhodesia, for preparing the photographs; and Mrs S. Munn for secretarial help.

\section{REFERENCES}

Edelstein, J. (1963) Quoted by Salter (personal communication).

Du Toit, G. T. (1974) Personal communication.

Gade, H. G. (1947) A contribution to the surgical treatment of osteoarthritis of the hip-joint. Acta chirurgica Scandinavica, 95, Supplement $120,32-290$

Huckstep, R. L. (1967) Quoted by Salter (1968).

Huckstep, R. L. (1970) Bilateral congenital dislocation of the hips in African twins. Journal of Bone and Joint Surgery', 52-B, 397.

Murray, R. O. (1965) The aetiology of primary osteoarthritis of the hip. British Journal of Radiology, 38, 810-824.

Putti, V. (1933) Early treatment of congenital dislocation of the hip. Journal of Bone and Joint Surgery, 15, 16-21.

Rosen, S. von (1962) Diagnosis and treatment of congenital dislocation of the hip joint in the new-born. Journal of Bone and Joint Surgery, 44-B, 284-291.

Salter, R. B. (1968) Etiology, pathogenesis and possible prevention of congenital dislocation of the hip. Camadian Medical Association Journal, 98, 933-945.

Trevor, D. (1967) Congenital dislocation of the hip. Physiotherapy, 53, 400-406.

Van Meerdervoort, H. F. P. (1974) Congenital dislocation of the hip in black babies. South African Medical Journal, 48, $2436-2440$.

Wynne-Davies, R. (1973) Congenital dislocation of the hip. In Heritable Disorders in Orthopaedic Practice, pp. 193-196. Oxford: Blackwell Scientific Publications. 